\title{
Rastros de 1968 nos artivismos das dissidências sexuais e de gênero
}

\author{
Marcelo de Trói' (iD) 0000-0001-9202-2829 \\ 'Universidade Federal da Bahia, Instituto de Humanidades, Artes e Ciências Professor \\ Milton Santos, Programa Multidisciplinar de Pós-graduação em Cultura e Sociedade, \\ Salvador, BA, Brasil.40170-115 - culturas@ufba.br
}

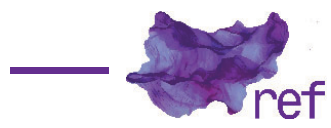

Resumo: O texto faz uma breve genealogia das questões relacionadas aos gêneros e às sexualidades que perpassam a "revolução mundial de Maio de 1968" e algumas das consequências políticas e sociais de seu potencial de desestabilização. Busca-se criar uma linha filiativa entre a revolução mundial, o início das discussões sobre gênero e sexualidade nas artes cênicas a partir do Teat(r)o Oficina e as atuais produções artísticas que se utilizam do corpo, da arte e do ativismo para enunciarem uma desobediência das normas, chamadas aqui de artivismos das dissidências sexuais e de gênero ou "a(r)tivismos queer".

Palavras-chave: Maio de 1968; artivismos; corpo dissidente; gênero e sexualidade; queer.

\section{8's Trail in Artivisms of Sexual and Gender Dissent}

Abstract: The article presents a brief genealogy of the issues related to the genres and sexualities that permeate the "May 1968 world revolution" and some of the political and social consequences of its potential for destabilization. It seeks to create a thread between the world revolution, the beginning of discussions on gender and sexuality in the performing arts from the Teat(r)o Oficina and the current artistic productions that use the body, art and activism to enunciate a disobedience of the norms, called here artivisms of sexual and gender dissent or "queer artivism".

Keywords: May 1968; artivisms; dissident body; gender and sexuality; queer.

\section{Introdução}

Em 2006, em Salvador, o espetáculo Guilda, dirigido por Marcelo Sousa Brito, apresentou diversos personagens que enfatizavam o absurdo, o irônico, com enfoque na sexualidade e no corpo. No ano seguinte, o grupo Solange Tô Aberta, projeto de Pêdra Costa, realizou performances musicais com o chamado 'funk proibidão' para expressar sexualidades e gêneros que questionam a heterossexualidade enquanto norma. Em 2013, no Rio de Janeiro, durante a Marcha das Vadias que coincidiu com a visita do Papa ao Brasil, uma manifestação do Coletivo Coiote ganhou as manchetes por conta de imagens de santos que foram quebradas e de cruzes introduzidas no cu dos performers. Em 2014, em festa na Universidade Federal Fluminense, sob o clima violento da reação do Estado quando das manifestações contra a Copa do Mundo no país, uma das performers do mesmo coletivo introduziu uma bandeira do Brasil em sua vagina, costurando o órgão genital em seguida. Durante a realização do II Seminário Internacional Desfazendo Gênero, em Salvador, em 2015, o performer Miro Spinelli lambuzou o seu corpo nu com dendê e os registros ${ }^{1}$ dessa performance, publicados na página do evento no Facebook, foram alvo de comentários transfóbicos e gordofóbicos, que culminou no encerramento da página do evento pela rede social. Na Bienal de Veneza de 2015, a 'bicha não binária' Jota Mombaça (como se define) delimitou fronteiras e escreveu com o próprio sangue no mapa mundi The colonial

Fotos do projeto artístico seriado Gordura Trans podem ser vistas no site do performer, disponível em https://www. mirospinelli.com/gordura-trans-trans-fat. Acesso em 23/01/2020. 
wound still hurts (A ferida colonial ainda dói). Em 2016, o Coletivo das Liliths, de Salvador, estreou o espetáculo Xica, contando a história daquela que teria sido a primeira travesti do Brasil, Francisco Manicongo (Deivide Souza de JESUS, 2019). Em BR Trans, de 2015, Silvero Pereira apresentou uma pequena liturgia cênica na qual denunciava a violência contra travestis e pessoas trans. Na música, nos últimos anos, Linn da Quebrada, Liniker, Johnny Hooker, em maior ou menor grau, impactaram o campo das artes e os mais conservadores com suas letras e seus corpos performáticos, embaralhando o jogo expresso nos binômios dos gêneros normatizados.

Esse parágrafo inicial ${ }^{2}$ traz uma amostra de produções artísticas e acontecimentos que marcam o surgimento de uma cena específica no Brasil nas duas últimas décadas. Dentre as causas da emergência dos chamados artivismos das dissidências sexuais e de gênero (Leandro COLLING, 2018; Marcelo de TRÓl; COLLING, 2017; TRÓl; COLLING, 2016) podemos citar o recrudescimento da violência contra a população LGBT; o aprisionamento do movimento gay institucionalizado à lógica cisgênera (Viviane VERGUEIRO, 2015)³, heteronormativa e 'bem-comportada'; a aposta no paradigma da igualdade e dos marcos legais sem considerar as estruturas discriminatórias presentes no próprio aparato estatal, debate já aprofundado por Nancy Fraser (2007) a respeito do crescente poder do neoliberalismo; o crescimento dos estudos de gênero e sexualidade no Brasil; a não adequação às normas corporais e comportamentais propagandeadas pelas instituições sociais; o advento das redes sociais como plataforma de divulgação e reverberação desses trabalhos, entre outros aspectos.

Em tempo de esgarçamento político e representativo, com forte violência endereçada aos corpos que não cumprem as expectativas da verdadeira 'ideologia de gênero' (TRÓl, 2019a), cisgênera, heterossexista e reprodutiva, as linguagens artísticas têm sido ferramentas potentes na atuação de coletivos, pessoas ativistas, performers e artistas interessadas em discutir padrões de comportamento. Mais do que isso, a arte tem sido fundamental na sobrevivência e visibilidade dessas pessoas, na busca de uma vida que importe (Judith BUTLER, 2000), o que fica evidente no caso da atriz Renata Carvalho, com o espetáculo $O$ evangelho segundo Jesus, Rainha do Céu, texto da britânica Jo Clifford. Renata atribuiu ao teatro o prolongamento de sua vida4, já que, no Brasil, a expectativa de vida de uma travesti é de 35 anos. Renata resistiu bravamente às inúmeras censuras que seu espetáculo sofreu em todo o país, mas, sobretudo por isso, tem encontrado uma rede de aliados que tem garantido a apresentação de sua Jesus travesti.

A emergência da desobediência de gênero e sexualidade enquanto temática nas artes é fruto de um longo caminho pavimentado por protagonistas anônimos e conhecidos, dentre os quais, mais recentemente, digo no século XX, especificamente no teatro brasileiro, destaca-se o Teat(r)o Oficina. Com seu 'te-ato' - depois grafado 'teat(r)o', elabora-se uma proposta estética e dramatúrgica que reinventa uma comunicação direta com o público, na qual a divisão de palco e plateia são superadas. Mais que isso, era um teatro que começava a furar a bolha da divisão esquerda/direita, com questões de classe expressas em espetáculos de grupos como o Arena e o Opinião, e inserir um componente anárquico, disruptivo e anticolonial. Presente em Paris em maio de 1968, José Celso Martinez Corrêa e seu elenco utilizariam a experiência para radicalizar as propostas cênicas que se engendravam desde a montagem de O rei da vela, em 1967:

A experiência de O rei da vela mudaria para sempre a maneira de interpretar do Teat(r)o Oficina, mas é em 1968, com Roda viva ${ }^{5}$, de Chico Buarque de Holanda, que o processo se radicalizou em relação à própria ideia de representação e dos tabus do corpo em cena. O espetáculo é a única encenação de Zé Celso fora do grupo, mas que se confunde com a própria história do Oficina por conta de seu diretor. Além disso, a experiência será determinante para a nova revolução cênica que está sendo engendrada depois do contato com a antropofagia de Oswald.

O espetáculo, naquele Brasil pré-Al5, torna-se um fenômeno ao contabilizar mais de 300 mil espectadores. (TRÓl, 2018, p. 41).

O te-ato abria os fluxos para uma relação libidinosa com a plateia e desvelava a presença revolucionária do corpo presente. Incorporando a rebeldia da época, Roda viva causa reações logo na estreia. Depois de assistirem ao espetáculo, dois deputados foram fazer críticas ao

2 Autores e argumentos presentes neste texto tiveram duas importantes contribuições: 1) a pesquisa coletiva desenvolvida no segundo semestre de $2018 \mathrm{com}$ Jean Tible, professor do departamento de Ciências Políticas da Faculdade de Filosofia, Letras e Ciências Humanas da Universidade de São Paulo, através do componente "Políticas dissidentes: a partir da revolução mundial de 1968"; 2) a pesquisa "As artes e as políticas das dissidências sexuais e de gênero no Brasil da atualidade" desenvolvida coletivamente na linha de pesquisa Artes, gêneros e sexualidades do Núcleo de Pesquisa e Extensão em Culturas, Gêneros e Sexualidades da Universidade Federal da Bahia (2016-2020) com financiamento do Conselho Nacional de Desenvolvimento Científico e Tecnológico (CNPq).

${ }^{3}$ Pessoa que se identifica com o gênero atribuído no nascimento, ou seja, a pessoa não transgênera. Em termos de normatividade, a cisgeneridade é o 'normal' ante a transgeneridade, ainda patologizada.

${ }^{4}$ A atriz fez um discurso emocionado quando da censura de seu espetáculo em Salvador (BA), em 2017. Graças a uma articulação de produtores locais, foi possível realizar a apresentação em local diferente do proibido pela liminar judicial.

5 Uma nova montagem do espetáculo Roda viva sob a direção de José Celso Martinez Corrêa ficou em cartaz no Teat(r)o Oficina, em São Paulo (SP), em 2019 e 2020. 
Oficina na televisão, com agressões pessoais, violentas e vários policiais e investigadores dentro do estúdio. Em discussões na Assembleia Legislativa de São Paulo, o espetáculo era acusado de obscenidade, pornografia e de agressão ao regime democrático. Roda viva incomodava ao colocar o corpo coletivo em cena, corpo de uma geração que não tinha nenhuma ilusão de "subir no sistema" (como dos jovens nas ruas de Paris), um coro que "avançou sobre o público, ocupou a sala, saiu pra rua e foi empurrado de volta para a jaula do palco, através dos dois atentados do Comando de Caça aos Comunistas" (José Celso MARTINEZ CORRÊA, 1998, p. 130).

Em muitos sentidos, essa mesma centralidade que o corpo ocupa na representação artística terá novo lugar nas recentes produções ativistas. Poderíamos pensar em uma 'linha de filiação' que propiciou o surgimento de um corpo dissidente nas artes, tendo a performance como veículo, em estreita relação entre o campo subjetivo e social. Das artes plásticas às cênicas, a performance possui longa trajetória de debate com nomes como Gina Pane, Joseph Beuys, Marina Abramovic e Annie Sprinkle, entre outros. Com a antropologia da performance, Victor Turner (1974) relaciona a performance à esfera ritual, sendo esta uma ruptura temporal e simbólica capaz de repensar os valores sociais hegemônicos. A partir dos estudos queer, Butler (2003) faz distinção entre performatividade e performance, sendo a primeira o poder reiterativo do discurso responsável pelo caráter "performativo" do gênero. Por sua vez, Renato Cohen (2002) fala em "colonização cultural" para explicar o advento da performance no Brasil e pensa esta como uma espécie de pré-história da linguagem, defendendo a performance como uma arte híbrida que escapa das delimitações disciplinares. Para Eleonora Fabião (2008), a performance é uma resposta momentânea para questões recorrentes, uma arte da criação, do aqui e agora. Como arte contemporânea, a performance desafiaria princípios classificatórios, evidenciando a "vulnerabilidade do vivo e da vivência" (FABIÃO, 2008, p. 239).

Desse modo, uma linha de filiação que encontra veículo na performance é pensada aqui com Gilles Deleuze e Félix Guattari (2010) que demonstram como essa última filiação é biossocial, vista como prática, um procedimento, uma estratégia. Os a(r)tivismos ${ }^{6}$ queer trazem uma filiação ligada ao corpo e dizem respeito às produções artísticas e ativistas que por sua vez trazem em seus enunciados uma desobediência de gênero e da sexualidade, além de formulações políticas em aproximação com o anarquismo e a luta anticolonial e antirracista (TRÓl, 2018).

Pensando em uma genealogia, as relações entre arte e ativismo remontam ao século XIX, passando pelos movimentos ligados aos direitos civis da segunda metade do século XX e à revolução mundial de Maio de 1968. Ao contextualizar 1968 como uma 'revolução mundial' deflagrada em uma série de eventos estudantis e operários que se espalharam por todos os continentes, Jean Tible tratou o acontecimento como uma libertação de vozes, na qual todos os aspectos da vida foram postos em xeque, em que ninguém cumpriu os papéis reservados na sociedade: "1968 marca o início do nosso mundo contemporâneo. Uma fenda no sistema de domínio, que provocou uma reação profunda, tanto política quanto econômica" (TIBLE, 2018, p. 14). Sem dúvida, são os eventos ligados ao pré e ao pós-revolução de 1968 que vão dar origem a um outro ativismo, horizontalizado, sem o destaque de lideranças, criativo, corporal, que culmina com as marchas antiglobalização do final dos anos 1990 e, já no século XXI, à estética da ocupação com a Primavera Árabe, Occupy Wall Street e de movimentos como Junho de 2013. Não há dúvidas de que as táticas das ocupações surgidas nas duas primeiras décadas do século XXI tenham como precursores movimentos surgidos na contracultura dos anos 1960 em países europeus, a exemplo dos movimentos Provos, Kraker, Squatters, dentre outros (Cleber RUDY, 2019).

Embora a ligação entre arte e ativismo, ou entre arte e política, sejam históricas, o termo artivismo não é um termo consensual para descrever esses eventos (André Luiz MESQUITA, 2008). 0 conceito instável é marcador de conflitos entre arte e política, principalmente aqueles que dizem respeito às instituições culturais e à relação com o lucrativo mercado das artes: "a arte ativista não significa apenas arte política, mas um compromisso de engajamento direto com as forças de uma produção não mediada pelos mecanismos oficiais de representação" (MESQUITA, 2008, p. 15). Paulo Raposo (2015) também ressaltou a "instável consensualidade" do termo tanto no campo das Artes como no das Ciências Sociais, mostrando que o artivismo se consolida como "causa e reivindicação social e simultaneamente como ruptura artística" (RAPOSO, 2015, p. 5). Se há tensão no que diz respeito ao conceito de artivismo, por outro lado, é consenso que o queer nasce do lugar da ofensa, do estranho, da marginalidade, da história apagada das travestis. Entretanto, o consenso do não lugar do queer não impediria a apropriação do termo pelo mercado da arte, a exemplo da exposição Queermuseu (Tiago SANT'ANA, 2017). Assim, recuperando a história do queer, são pessoas como Sir Lady Java e Marsha P. Johnson que, nos anos 1960, foram precursoras na defesa do trabalho das drag queens e dos direitos civis, respectivamente em Los Angeles e Nova lorque. Especialmente Marsha, uma das figuras-chaves da revolta de Stonewall (COLLING, 2011 ), em 1969, foi fundamental para a ascensão do movimento LGBT.

${ }^{6}$ Ao grafar o neologismo 'a(r)tivismo' em minha investigação (TRÓl, 2018), visava justamente ressaltar a instabilidade do termo e ligá-lo com o "teat(r)o" da companhia Oficina, estabelecendo uma conexão entre os campos. 
Esses cruzamentos entre arte, artivismo, gênero e sexualidade também vão acontecer em outras linguagens. O coletivo General ldeal (1969-1994) e a revista que produziam, a File (19721989), anteciparam a linguagem do fanzine punk e queer. Como demonstra Mesquita (2008), essas produções eram marcadas por artistas e ativistas impactados pelo surgimento do hiv-aid\$ (Ramon FONTES, 2019). Nessa direção, é o trabalho do ACT UP - Aids Coalition to Unleash Power - que vai redimensionar o papel da arte no ativismo queer. O ACT UP nasce em 1987, em plena era Reagan, marcada pela austeridade econômica e pelas políticas anti-hiv-aid\$̦. Com manifestações criativas e impactantes, o grupo passa a ser um marco na aproximação entre o ativismo, a arte e o queer. Na Bienal de Veneza de 1990, o Gran Fury, grupo surgido do ACT UP, leva cartazes para denunciar o posicionamento negligente da Igreja Católica ao condenar o uso da camisinha. Um dos pôsteres dizia: "42 mil pessoas mortas, arte não é suficiente" (MESQUITA, 2008, p. 130).

Da rua para os círculos acadêmicos, o queer se torna um campo de estudos que vai se desenvolver de formas variadas em diversos países e provocando tensões ao revelar os "pressupostos heterossexistas" da teoria social (Richard MISKOLCl, 2009). O novo campo rejeitou a ideia de minoria, admitindo que o sujeito é uma construção cultural e do discurso (BUTLER, 2003). Além disso, os estudos queer entendem que existe um regime de diferenciação na sociedade, a partir de uma matriz que conjuga gênero, sexo e prática, cisgênera e heterossexista, e que pune corpos que não obedecem a tal lógica (BUTLER, 2016). Desnaturalização e desconstrução serão os pilares desses estudos, mostrando que no jogo da presença e da ausência, as lógicas binárias e o 'natural' não passam de regimes de verdade construídos historicamente. O queer como lugar da ação política luta contra o risco de se transformar em identidade porque é um "processo de proliferação de estratégias de resistência à normatização" (Paul PRECIADO, 2017, p. 239).

\section{Insurgências}

Defendo que a emergência da cena descrita neste texto, embora encontre, como dito, uma linha de filiação que remonta ao século XIX, ganha força a partir dos anos 1960. Um caráter insurgente permeia essa época. Insurgência aqui compreendida como um desejo de "sublevarse, amotinar-se, revoltar-se, emergir, surgir de dentro, reagir, opor-se, tudo sinônimos próximos do desejo insurrecional" (RAPOSO, 2015), o que vai marcar o espírito dos artivismos. Os eventos que culminaram no acontecimento Maio de 1968 foram responsáveis por desarranjar a ilusão binária, no campo social e no campo subjetivo, marcando uma espécie de luta pelo direito de discordar, direito ao dissenso e o direito de se produzir novas formas de ontologias, de política e também de pesquisa.

Sem dúvida, um dos marcos de uma nova maneira de se produzir Ciência foi o Caucus for a New Political Science (CNPS), de 1967. Cansados das teorias behavioristas, com base nas pesquisas qualitativas da Escola de Chicago, um grupo de cientistas defendeu libertar as ciências das técnicas comportamentais. E a aposta nos dados qualitativos poderiam contribuir para um outro entendimento dos fenômenos. Além disso, advogava-se uma nova ciência política que fosse relevante e compromissada com a ética, empenhando 'forças por um mundo melhor'. Na época, pesava entre a comunidade científica dos Estados Unidos, o mito da 'ciência do valor livre', uma espécie de Escola Sem Partido ${ }^{7}$ que acreditava na neutralidade do conhecimento, para assim manipulá-lo ideologicamente sob o carimbo da isenção. O Caucus colocou "em xeque os pressupostos das ciências sociais" (Clyde BARROW, 2017, p. 440), pavimentando o caminho para o surgimento de propostas teóricas como a queer, a qual vai questionar no final dos anos 1980 e início dos 1990, o poder de neutralidade dos pesquisadores heterossexuais que se ocupavam das minorias, revelando que a suposta objetividade também era atravessada por questões subjetivas.

Espécie de tratado que tem origem em 1972, ainda sob os rastros de 1968 e prenhe de suas ideias, O anti-Édipo, livro de Deleuze e Guattari (2010), subtitulado Capitalismo e Esquizofrenia, demonstra que o binômio e a tríade são modos de pensar ligados à formação de um espírito colonial identificado como complexo de Édipo: "Somos todos pequenas colônias, e é Édipo que nos coloniza" (DELEUZE; GUATTARI, 2010, p. 351). Essa ideia freudiana universal não sobreviveria ao contato com a cultura e a cosmogonia de uma tribo do Alto Xingu. O fato é que a partir dos ' $n$ ' sexos, das multiplicidades e alianças como novos arranjos ontológicos, não apenas instituições (molaridade) foram obrigadas a pensar em novos regimes de inteligibilidade, mas também o campo subjetivo e inconsciente (molecular) foi fortemente afetado, modificando as noções que nós temos sobre sujeito, ideologia, gênero e sexualidade. Para os filósofos, o molar está no nível institucional e o molecular no nível inconsciente. Deleuze e Guattari, que participaram ativamente do Maio de 1968, acreditavam que um fluxo molecular escapava ali, mas depois esse fluxo irrompeu por todas as estruturas e organizações molares, remanejando as "distribuições binárias de sexos, de classes, de partido" (DELEUZE; GUATTARI, 2012, p. 104).

${ }_{7}$ Criado em 2004, o chamado movimento Escola Sem Partido torna-se conhecido em 2014 durante os debates do novo Plano Nacional de Educação. O movimento é um dos principais responsáveis pela difusão do termo 'ideologia de gênero' e pode ser considerado uma das marcas da ascensão da extrema direita no Brasil (TRÓl, 2019a). 
A revolução mundial de Maio de 1968 é um acontecimento tão importante que seus efeitos na política, na cultura e na produção do conhecimento ecoam até hoje, e muitos dos seus questionamentos continuam valendo nessa espécie de "futuro do subjuntivo histórico" que, como afirma Eduardo Viveiros de Castro (2015, p. 100), faz com que o evento ainda não tenha terminado ou "talvez sequer tenha começado". Outro fato recorrente para descrever os eventos de 1968 e também as Jornadas de 2013 é a falta de um 'objetivo', característica que Raposo (2015) também atribuiu aos artivismos que, como uma insurgência política, não contêm propriamente 'um plano de transformação social'. Contudo, apesar de todas as contradições possíveis do evento que está longe de ser uniforme, exceto pela agitação urbana mundial no final dos anos 1960 e início dos 1970, é preciso concordar que se 1968 não ofereceu respostas, ao contrário, inventou novos problemas, um algo de "inassimilável que escapava", como afirmaram Deleuze e Guattari (2012), porque se tratava de uma revolução molecular.

O remanejo do binarismo vai ser sentido, principalmente, nas definições sobre gênero e sexualidade. Tudo feito e dito com criatividade e violência por uma juventude que estava cansada de estruturas sociais sufocadas pelo jogo das hegemonias econômicas no poder. O caráter performativo do movimento também não deixará de influenciar grande parte das manifestações públicas nas ruas desde então.

Entre os efeitos dessa revolução estão outras formas de se fazer política, retirando do Estado e das instituições o protagonismo soberano de decisão das nossas vidas e desejos. Fica evidente que é a partir de 1968 que muitas das vozes historicamente silenciadas passaram a ser ouvidas: mulheres, pessoas negras, LGBTQIA+ e outras populações minorizadas. Ao mesmo tempo, fica evidente que o Estado contemporâneo, organizado em função dos poderes constituídos e do próprio capital, seria incapaz de atender as demandas de toda a população.

Foram as mulheres, as principais pensadoras daquele tempo, que abriram campo para as lutas do movimento gay e revelaram como a sociedade, apesar da ideia de uma democracia participativa e humanitária instituída no pós-guerra, ainda estava sob o domínio do homem branco. Assim, nomes como Angela Davis surgem em fim dos anos 1960 e início dos 1970 para colocar em xeque o poder instituído nos Estados Unidos. Davis (1981) lançaria um dos marcos da segunda onda feminista Women, race \& class. O ano de 1968 também marcou o lançamento de The first cities, primeiro livro de outra referência para o feminismo negro, Audre Lorde (1968).

Valerie Solanas (1971) ficou conhecida pela tentativa de assassinato do artista Andy Warhol, em 1968, depois deste não ter devolvido um roteiro que ela teria entregado para que ele filmasse. A escritora identificou o patriarcado nas relações de poder e, apesar do caráter transfóbico de algumas declarações presentes em seu manifesto, ela não deixou de captar a disjunção de gênero e de sexualidade que se evidenciava naquela época. Mesmo como mulher branca com seus privilégios, foi a primeira a afirmar-se como lésbica, feminista, trabalhando como prostituta. Seu SCUM Manifesto, Society for Cutting Up Men, pregava um verdadeiro 'holocausto macho', dirigindo sua violência para a família e o American way of life.

Maria Rosa Dalla Costa (1972) também influenciou as políticas dissidentes como mulher italiana no pós-guerra, que captou qual era a relação da mulher com o capital e qual tipo de luta deveria ser feita para destruir tal relação. Sem dúvida, uma das pioneiras em identificar a figura do 'esquerdomacho's, sem assim nomeá-lo, Dalla Costa vai denunciar como a luta de classe, enviesada por um olhar masculino, desconsiderava os problemas que afligiam as mulheres.

Pensando o capitalismo como a política que eleva a heterossexualidade como religião, Dalla Costa frisou a função do útero para a sociedade capitalista, explicitando os caráteres normativos que incidiam sobre o corpo feminino, através das diferenciações entre a mulher casada e a solteira e da dupla jornada feminina, na fábrica e em casa, produzindo mais-valia para um sistema altamente masculino.

De todas as mudanças que se davam em vários lugares do mundo desde o início dos anos 1960 relacionadas a discriminação racial, religiosa ou por nacionalidade, o gênero ficava de fora. Mas, a partir de 1965, nos Estados Unidos, por exemplo, tornou-se ilegal a prática de anúncios nos jornais, de seleção de empregos a partir do gênero (Mark KURLANSKY, 2005), na qual os salários oferecidos para as mulheres eram sempre menores.

Sendo assim, o período anterior e posterior, ou seja, as causas e consequências do Maio de 1968, parecem revelar não apenas a frustração com os espectros à esquerda e à direita da política que engendravam relações estruturais com o poder ${ }^{9}$, mas também um diagnóstico de que as estruturas discriminatórias ligadas à sociedade funcionavam a partir de uma distinção de gênero. Assim, o movimento LGBT (até então sem as multiplicidades contemporâneas do alfabeto

${ }^{8}$ O termo contemporâneo denota a tensão entre a esquerda e o feminismo. O termo surge na era das redes sociais para caracterizar o homem, em geral heterossexual, que é de esquerda, mas que é atravessado pelo machismo, diminuindo o valor e a representação das mulheres e considerando questões relacionadas ao gênero, à sexualidade, ao aquecimento global, por exemplo, como questões 'menores'.

9 A premissa do perigo do poder, independentemente de qual ideologia esteja no comando, é um dos pressupostos do trabalho do artista contemporâneo Ai Wei Wei: "onde há poder, há perigo" era uma das frases expostas na exposição do artista chinês realizada em 2018, na Oca do Parque do Ibirapuera, na cidade de São Paulo (SP). 
de identidades sexuais e de gênero do século XXI) já despontava como aquele mais apto a desengajar as ligações da sexualidade e do gênero com o poder, tal e qual a máxima criada pelo poeta Roberto Piva (2006, p. 142) inspirado nos gays espanhóis: "o coito anal derruba o Kapital".

\title{
Corpo dissidente
}

Se há uma política dissidente a partir de Maio de 1968, esta só poderia ser operada por um corpo que se recusa às ideias hegemônicas sintonizadas com a ideia de normalidade previstas e transformadas em tecnologias desde o nascimento do mundo moderno. Ao cartografar a rede de poder e disciplinamento que costura a modernidade, Michel Foucault (2009) vai demonstrar que onde há poder, há resistência, ou melhor dizendo 'resistências' (no plural), já que não está posto um lugar de 'grande recusa'. Daí que:

\begin{abstract}
Se tomar posse do corpo é tomar posse do mundo e daquilo que somos, não é difícil imaginar que, tão logo se estabeleça as normas e a própria disciplinaridade no mundo moderno, nasça também aí um tipo de resistência. É a diferenciação operada entre o "normal" e o "anormal" que vai validar conhecimentos altamente discriminatórios, no qual a medicina, as escolas e, posteriormente, os conhecimentos psi vão determinar os corpos que serão considerados "outros". Domínios privados que se tornam públicos e políticos. A partir disso, os "outros" serão vilipendiados, executados, principalmente para a implantação lenta e sistemática do grande projeto moderno e capitalista. (TRÓl, 2018, p. 110).
\end{abstract}

Richard Sennett (2003) colocava que o espaço urbano é responsável pelas vivências corporais de cada época, e a corporeidade ideal vai se modificando com o desenvolvimento das cidades, onde as imagens idealizadas do corpo "cumprem a função da autoridade no espaço urbano" (SENNETT, 2003, p. 302). Para ele, em uma sociedade ou ordem política que enaltece genericamente o corpo, "corre-se o risco de negar as necessidades dos corpos que não se adéquam ao paradigma" (SENNETT, 2003, p. 22). Esse processo de diferenciação condicionado às regras e normas e aos paradigmas de grupos hegemônicos, produz corpos inconformes, não recomendados.

É possível que a modernidade, com seu ideal de sociedade altamente organizada, disciplinada, tenha dado mais fortemente os sinais de seu fracasso a partir de 1968, que pode ser considerado um grande marco disjuntivo. Na década anterior, o sexo e a sexualidade foi o centro da atividade política e econômica, conforme nos ensina Preciado (2018). A perseguição à homossexualidade com o macarthismo, nos anos 1950, a criação do conceito de gênero e a criação da pílula anticoncepcional em 1957 demonstram que, não podendo dominar por completo os fluxos que diziam respeito ao corpo e ao desejo, restava ao sistema interferir na força orgásmica que vai substituir a força de trabalho no que Preciado denomina como era farmacopornográfica, na qual "o corpo já não habita os espaços disciplinadores, está habitado por eles" (PRECIADO, 2018, p. 86); a gestão do desejo, a potentia gaudendi (potencialidade masturbatória) isto é, o poder de produzir prazer molecular, está habitada por toda ordem de componentes químicos (pílula anticoncepcional, contra a disfunção erétil, antidepressivos, pornografia aliada a tecnologia e dados digitais).

Com sua reflexão e autoexperimentação de testosterona, princípio da autocobaia já experimentado por Sigmund Freud (Peter GAY, 1998 apud PRECIADO, 2018), Walter Benjamin (2006), entre outros ${ }^{10}$, Preciado pensa de que maneira é possível construir um corpo dissidente que fura 0 bloqueio da regulamentação estatal sobre os corpos, desfazendo os gêneros e subvertendo seu caráter performativo e discursivo.

A utilização do termo 'dissidência' aqui surge para se afastar da ideia de 'diversidade', que ficou popularizada ao se tratar de assuntos ligados às temáticas LGBT. Contudo, o termo diversidade está atrelado à questão multicultural' (Stuart HALL, 2003), em supostas negociações e convivências que não consideram as estruturas de opressão social e diferenças de acesso à justiça, com um "vago e benevolente apelo à tolerância" (Tomaz Tadeu da SILVA, 2000, p. 69), expressão considerada também demasiada "normalizada" e "neoliberal" (Felipe Rivas SAN MARTIN, 2011 apud COLLING, 2015, p. 151).

Dissidente é um conceito pós-identitário e, ao contrário da diversidade, com sua ideia utópica de tolerância consensual, o corpo dissidente opera pelo dissenso. O corpo dissidente não quer ser submisso, organizado - e aqui vale evocar o conceito de Corpo Sem Órgãos ${ }^{11}$, de

\footnotetext{
${ }_{10}$ Paul Preciado $(2018$, p. 370) defende que quem quiser ser sujeito político precisa ser o "rato de seu próprio laboratório". Ao narrar sua pesquisa-experimentação, Preciado demonstra como o princípio da autocobaia encontra recorrência na própria Ciência e para isso cita Freud, Benjamin e Mikhail Bulgákov: "A inclinação de Freud para a absorção de novas tecnologias de modificação da subjetividade não se limita aos testes e ao uso de drogas. Freud não hesita em utilizar o próprio corpo como terreno de experimentação cirúrgica, inclusive se tiver que colocar os próprios testículos em jogo" (PRECIADO, 2018, p. 375).

${ }^{11}$ Artaud (1974) fala do conceito no texto Para dar um fim no juízo de deus, escrito em 1947. "Para se compreender o conceito de Corpo Sem Órgão - CsO, em Deleuze e Guattari (2010), pensemos que, para Artaud, os órgãos fazem
} 
Antonin Artaud (1974), posteriormente utilizado para as reflexões de Deleuze e Guattari (2010) - e se articula nos ofícios de artistas e ativistas que fazem valer o papel desviante da arte, o que fica nítido nas produções do Teat(r)o Oficina e nas produções dos a(r)tivismos. Mas também devemos pensar o corpo dissidente como

o corpo ciclista que afronta a norma carrocrata, o corpo dissidente na inconformidade de gênero que afronta a norma de gênero, a cisnormatividade e a própria deliberação do que deve ser o corpo feminino ou masculino. O corpo senil, a corpa flamejante com o fogo na raba, o movimento da cintura e dos gestos que perturbam o outro, sempre no local do defensor e cúmplice dos paradigmas coloniais; corpo dissidente que tem a potência da desaprendizagem, a desnaturalização, processo decolonial permanente, luta permanente, movimento permanente. Uma desconstrução que tem um fim: o homem branco ocidental, símbolo do patriarcado, um modelo hegemônico, um ideal a ser alcançado pela ideologia de gênero heterossexista que atrai, inclusive, as diferenças, já que todos, sem distinção, somos atravessados pelo molar e pelo molecular, pelas matrizes coloniais compulsórias. Desconstrução essa que será em prol das culturas que foram e são silenciadas, saberes e histórias da diáspora africana, indígena, travesti e transgênera, o próprio silenciamento da Terra e seu hábitat devastado pelo capitalismo. (TRÓl, 2018, p. 117).

Dessa forma, o corpo dissidente presente nesse novo ativismo vai em direção às identidades múltiplas e transitórias, em estados de performance e existências simbióticas que flertam com a monstruosidade e o animal: a artista Susy Shock reivindica o direito de se tornar monstra (COLLING, 2015), a performer Malayka SN e as Estranhas Marujo, de Salvador, vão ser vampiras pós-apocalípticas em sua 'monxtração' de drag queer pela qual não são apenas queens, nem divas. Diana Torres, performer espanhola, é a pornoterrorista que se define como bizarra, porque:

Se o levante surge como gesto, o corpo dissidente é inexoravelmente um corpo que se subleva, é o agente de um levante nem sempre silencioso, mas visível, que cria uma disjunção nas normas, opera nas falhas do ato performativo que dá ferramentas para a produção de performances contra-hegemônicas. É a vingança da drag, da monstra, das travestis, da multidão queer. Se Didi-Huberman [(2017)] identifica o "levantar o braço" como esse gesto inscrito na história, e isso fica evidente a partir das obras de arte que ele reúne em sua análise e em sua curadoria, mexer a raba, dar pinta e fechar também são gestos produzidos pelo corpo dissidente que estão sendo escritos na história neste nosso momento histórico, confirmando que o que nos torna protagonistas de levantes são os nossos desejos, ou seja, gestos pelos quais os corpos desprovidos de poder manifestam uma potência fundamental. (TRÓl, 2018, p. 123).

Os artivismos vão lidar com nosso inconsciente colonial, no qual os fluxos são codificados de maneira a nos inserir na seara do desejo normatizado, da obediência, no conhecimento dominado pela paranoia e pela axiomática (DELEUZE; GUATTARI, 2010), dispositivos de reinserção de qualquer fluxo libertário no consumo e na lógica capitalística.

\section{Consideraçōes finais}

É preciso enxergar essa cena emergente sobre muitos prismas que não cabem em um texto ou uma análise. Neste artigo, a ideia foi demonstrar como muitas das estratégias desses coletivos e artistas se conectam às estratégias postas na revolução mundial de Maio de 1968. E aqui reitero, não se tratou de um movimento dos universitários brancos nas ruas de Paris gritando palavras de ordem. As insurgências provocadas pela disjunção política e subjetiva presente naquela época aconteceram em diversos pontos do globo que, na ocasião, ainda não dispunha da comunicação instantânea da internet. Maio de 1968 expressou autonomia e reativação das práticas, a explosão de demandas sociais, de luta por direitos civis, o que gerou uma contraofensiva, uma reação-repressão dos poderes que viram "um excesso de democracia" (TIBLE, 2018, p. 14). Não à toa, foi nesse período que vimos o assassinato de líderes como Malcom X, em 1965, e Martin Luther King, em 1968. Desde então, muitos dos dilemas já postos naquela época continuam presentes até hoje, como se fôssemos perseguidos por um fantasma histórico, "uma sobreposição de fins de mundo (capitalismo com democracia representativa e estado de bem-estar, socialismo autoritário, projetos de libertação nacional, planeta com a mudança geológica do capitaloceno ${ }^{12}$ ) nos desafia" (TIBLE, 2018, p. 18).

Os a(r)tivismos se utilizam da arte e do desejo como aspectos revolucionários, libertando o corpo docilizado e normatizado em busca de outros fluxos. Para esses grupos, falar sobre desejo será falar de política e "pensar a política não ocorrerá sem um pensamento do desejo" (DIDI-HUBERMAN, 2017, p. 339). Nesse ínterim, a recusa às normatividades e ortopedia dos corpos tem sido uma das

parte do organismo que sofre diversos investimentos a partir do campo social. Ao atacarem o Complexo de Édipo freudiano, os filósofos vão demonstrar como ele representa um investimento e controle total dos órgãos a partir do paradigma triangular do pai e da mãe" (TRÓl, 2018, p. 18).

${ }_{12}$ Capitaloceno tem sido um dos termos usados para definir a era atual que marca o ser humano como força geológica (Antropoceno). Aqui, o enfoque está nos efeitos do capitalismo, evitando distribuir de forma equânime as responsabilidades pela destruição dos ecossistemas. 
táticas mais poderosas desse novo ativismo, pois nessa recusa está inserida também uma potência de "fazer de outro modo" e na capacidade de se compor alianças e inventar "novas formas de viver e agir" (DIDI-HUBERMAN, 2017, p. 344). E não foram exatamente esses os pressupostos da revolução mundial de Maio de 1968?

Fazer de outro modo, se articular com a história de diferentes saberes e seres sem os quais "outro mundo não será possível", como afirma Walter Mignolo (2015, p. 309). Isso se traduz em ir de encontro ao inconsciente colonial e às noções e conhecimentos antropo e eurocentrados. Modificar os entendimentos de que temos sobre o corpo, pensando os corpos geopoliticamente e em cruzamento com raça, gênero e sexualidade. Falas localizadas que surgem dos feminismos negros (Djamila RIBEIRO, 2017) e dizem respeito à voz e escuta de vozes marginalizadas, vozes que foram amplificadas no pré e pós 1968, e que são importantes para se pensar em distribuição de violência e em um equilíbrio social que não seja pautado pela ótica dos grupos que detêm hegemonia.

Assim, a nova guinada mundial à direita e à extrema direita, especificamente no Brasil (Esther SOLANO, 2018), pode ser vista como um medo e uma reação à revolução molecular disparada a partir de 1968. Isso inaugura um novo período de disputas das narrativas que permeiam questões que envolvem os a(r)tivismos queer e colocam em oposição o discurso biológico (natural) e o cultural, uma velha questão antropológica (Philippe DESCOLA, 2016), e revela, sobretudo, os regimes de verdade validados historicamente a partir de uma perspectiva de imposição de saberes do dispositivo modernidade/colonialidade (Aníbal QUIJANO, 2005), que desconsidera as várias formas de compreender a materialidade do corpo, este corpo que continua sempre 'a escapar'.

Para além da materialidade física, nossos corpos são frutos do poder reiterativo do discurso, à medida que é o discurso que define as práticas, as categorias e os modos de ser socialmente. É o discurso que materializa a "norma regulatória" (BUTLER, 2000, p. 158) e isso será fundante no que diz respeito às discussões contemporâneas sobre os gêneros e as sexualidades cujas produções do a(r)tivismos vão problematizar com tanta ênfase.

Os a(r)tivismos queer encontram aí o seu ponto principal de questionamento, desafiando as normas reguladoras disciplinares e farmacopornográficas, reinventando novas formas de resistência com a mesma força das ruas de Paris, em 1968, ou da Universidade de Berkeley, em 1969. Essa arte ativista e desobediente se conecta a novas ontologias, muitas vezes monstruosas e pós-humanas (TRÓl, 2019b), apontando que resta a esse corpo dissidente gerado nas artes, mas também no campo social, insurgir-se contra quem dirige a violência.

Esse Estado que está aí e que desde o início esteve imbricado com o Capital e as forças repressoras (DELEUZE; GUATTARI, 2010), e que precisa do racismo para operar sua lógica discriminatória (FOUCAULT, 2009), dificilmente poderá atender ao clamor da gente da Terra. É que o neoliberalismo, essa doutrina do choque (Naomi KLEIN, 2008), nasce como uma teoria da crise, do desastre, que ele mesmo desencadeia, sob a lógica militar do inimigo interno, culpando o Estado, do qual ele, paradoxalmente e simbioticamente, ocupa e extrai todos os recursos em função do capitalismo global.

Os artivismos, em plena conexão com diversos movimentos sociais, procuram a reinvenção da própria vida, da cidade, e partem de um movimento no qual a utopia não dá conta, muito menos as promessas de paraíso futuro. E por acaso, essa não foi uma das lições de Maio de 1968 ? A estratégia era fazer com as próprias mãos e não esperar por mais ninguém, sobreviver diante da adversidade. Nessa direção, os artivismos têm sido uma maneira de corpos não viverem como fantasmas diante de um planeta que colapsa ante a ferocidade daqueles que se seguram no que podem para evitar um mundo comum. Só tem restado às dissidências, como aos jovens sonhadores de 1968, a insurgência.

\section{Referências}

ARTAUD, Antonin. "Pour finir avec le jugement Dieu". In: ARTAUD, Antonin. Oeuvres completes. Paris: Édition Galimard, 1974. p. 84-86.

BARROW, Clyde. "The political and the intellectual origins of new political science". New political science, London, v. 39, n. 4, p. 437-472, out. 2017.

BENJAMIN, Walter. On Hashish. Cambridge: Harvard University Press, 2006.

BUTLER, Judith. "Corpos que ainda importam". In: COLLING, Leandro (Org.). Dissidências sexuais e de gênero. Salvador: EDUFBA, 2016. p. 20-42.

BUTLER, Judith. Problemas de gênero: feminismo e subversão da identidade. Rio de Janeiro: Civilização Brasileira, 2003. 
BUTLER, Judith. "Corpos que pesam: sobre os limites discursivos do sexo". In: LOURO, Guacira Lopes. O corpo educado: pedagogias da sexualidade. Belo Horizonte: Autêntica, 2000. p. 151-166.

COHEN, Renato. Performance como linguagem: criação de um tempo espaço como experimentação. São Paulo: Editora Perspectiva, 2002.

COLLING, Leandro. "A emergência dos artivismos das dissidências sexuais e de gêneros no Brasil da atualidade". Sala Preta, São Paulo, v. 18, n. 1, p. 152-167, jun. 2018. Disponível em https://doi. org/10.11606/issn.2238-3867.v18i1p152-167. Acesso em 17/08/2018.

COLLING, Leandro. Que os outros sejam o normal: tensões entre movimento LGBT e ativismo queer. Salvador: EDUFBA, 2015.

COLLING, Leandro (Org). Stonewall 40 + o que no Brasil? Salvador: EDUFBA, 2011.

DALLA COSTA, Maria Rosa. JAMES, Selma. The power of women and the subversion of the community. Londres: Falling Wall Press, 1972.

DAVIS, Angela. Women, race \& class. Nova York: Random House, 1981.

DELEUZE, Gilles; GUATTARI, Félix. O anti-Édipo: capitalismo e esquizofrenia. São Paulo: Editora 34, 2010.

DELEUZE, Gilles; GUATTARI, Félix. Mil platôs: capitalismo e esquizofrenia 3. São Paulo: Editora 34, 2012.

DESCOLA, Philippe. Outras naturezas, outras culturas. São Paulo: Editora 34, 2016.

DIDI-HUBERMAN, Georges. (Org.). Levantes. São Paulo: Edições Sesc, 2017.

FABIÃO, Eleonora. "Performance e teatro: poéticas e políticas da cena contemporânea". Sala Preta, São Paulo, v. 8, p. 235-246, nov. 2008. Disponível em http://www.revistas.usp.br/salapretal article/view/57373/60355. Acesso em 18/01/2020.

FONTES, Ramon. "2019: a revolução dos vírus ou uma odisseia no espaço brasileiro". Revista Periódicus, Salvador, v. 1, n. 11, p. 112-126, maio/out. 2019. Disponível em hittps://portalseer.ufba. br/index.php/revistaperiodicus/article/view/29295. Acesso em 20/01/2020.

FOUCAULT, Michel. A história da sexualidade 1: a vontade de saber. Rio de Janeiro: Edições Graal, 2009.

FRASER, Nancy. "Mapeando a imaginação feminista: da redistribuição ao reconhecimento e à representação". Revista Estudos Feministas, Florianópolis, v. 15, n. 2, p. 291-308, maio 2007. Disponível em https://periodicos.ufsc.br/index.php/ref/article/view/S0104-026X2007000200002. Acesso em 16/01/2020.

HALL, Stuart. Da diáspora: identidades e mediações culturais. Belo Horizonte: Editora UFMG, 2003.

JESUS, Deivide Souza de. Artivismos das dissidências: colaborações interseccionais baianas ao teatro negro. 2019. Mestrado (Programa Multidisciplinar de Pós-graduação em Cultura e Sociedade) - Instituto de Humanidades, Artes e Ciências da Universidade Federal da Bahia, Salvador, BA, Brasil.

KLEIN, Naomi. A doutrina do choque: a ascensão do capitalismo de desastre. Rio de Janeiro: Nova Fronteira, 2008.

KURLANSKY, Mark. 1968: o ano que abalou o mundo. Rio de Janeiro: José Olympio, 2005.

LORDE, Audre. The first cities. Michigan: Poet Press, 1968.

MARTINEZ CORRÊA, José Celso. Primeiro ato: cadernos, depoimentos, entrevistas (1958-1974). São Paulo: Editora 34, 1998.

MESQUITA, André Luiz. Insurgências poéticas: arte ativista e ação coletiva (1990-2000). 2008. Mestrado (Programa de Pós-graduação em História) - Faculdade de Filosofia, Letras e Ciências Humanas da Universidade de São Paulo, São Paulo, SP, Brasil.

MIGNOLO, Walter. Trayectorias de re-existencia: ensayos en torno de la colonialidad/decolonialidad del saber, el sentir y el creer. Bogotá: Universidad Distrital Francisco José de Caldas, 2015. 
MISKOLCl, Richard. "A Teoria Queer e a Sociologia: o desafio de uma analítica da normalização". Sociologias, Porto Alegre, ano 1 1, n. 21, p. 150-182, jan./jun. 2009. Disponível em hittp://www.scielo. br/pdf/soc/n21/08.pdf. Acesso em 17/08/2018.

PIVA, Roberto. "Mala na mão \& asas pretas". In: PIVA, Roberto. Obras reunidas 2. São Paulo: Globo, 2006. p. 142-152.

PRECIADO, Paul. Testo junkie: sexo, drogas e biopolítica na era farmacopornográfica. São Paulo: $\mathrm{N}-1$ edições, 2018.

PRECIADO, Paul. "Cartografia queer: o flâneur perverso, a lésbica topofóbica e a puta multicartográfica ou como fazer uma cartografia 'zorra' com Annie Sprinkle". Performatus, Inhumas, ano 5, n. 17, p. 1-32, jan. 2017. Disponível em https://performatus.net/traducoes/cartografiasqueer/. Acesso em 21/01/2018.

QUIJANO, Aníbal. "Colonialidade do poder, eurocentrismo e América Latina". In: LANDER, Edgardo (Org.). A colonialidade do saber: eurocentrismo e ciências sociais. Buenos Aires: CLACSO, 2005. p. 107-127.

RAPOSO, Paulo. "Artivismo: articulando dissidências, criando insurgências". Cadernos de Arte e Antropologia, Lisboa, vol. 4, n. 2, p. 03-12, out. 2015. Disponível em hittp://cadernosaa.revues. org/909. Acesso em 21/01/2020.

RIBEIRO, Djamila. O que é lugar de fala? São Paulo: Editora Letramento, 2017.

RUDY, Cleber. "Outra Face das Cidades: Intervenções (não institucionais) do espaço urbano - os squatters". Revista O Olho da História, Salvador, v. 1, n. 3, p. 1-16, mar. 2019. Disponível em http:/l oolhodahistoria. ufba.br/wp-content/uploads/2019/03/squatters-cleber.pdf. Acesso em 20/01/2020.

SANT'ANA, Tiago dos Santos. "Queermuseu: a apropriação que acabou em censura". Le Monde Dip/omatique [online], São Paulo, 2017. Disponível em hittp://diplomatique.org.br/queermuseu-aapropriacao-que-acabou-em-censural. Acesso em 23/10/2017.

SENNETT, Richard. Carne e pedra. Rio de Janeiro: Record, 2003.

SILVA, Tomaz Tadeu. (Org). Identidade e diferença: a perspectiva dos Estudos Culturais. São Paulo: Editora Vozes, 2000.

SOLANAS, Valerie. SCUM Manifesto. Londres: The Olympia Press, 1971.

SOLANO, Esther. "Crise da democracia e extremismo de direita". Análise - Friedrich-EbertStiftung, São Paulo, n. 42, p. 1-29, maio 2018. Disponível em http://library.fes.de/pdf-files/bueros/ brasilien/14508.pdf. Acesso em 16/08/2018.

TIBLE, Jean. "Brechas que inspiram: Maio de 68 em nós". Revista Outubro, Rio de Janeiro, v. 1, n. 30, p. 7-20, maio 2018.

TRÓl, Marcelo de. Corpo dissidente e desaprendizagem: do Teat(r)o Oficina aos a(r)tivismos queer. 2018. Mestrado (Programa Multidisciplinar de Pós-graduação em Cultura e Sociedade) - Instituto de Humanidades, Artes e Ciências da Universidade Federal da Bahia, Salvador, BA, Brasil.

TRÓl, Marcelo de. "Direitos sexuais e identidade de gênero são direitos humanos: onde está a ideologia?" In: CALAZANS, Márcia Esteves de; MALOMALO, Bas'llele; PIÑERO, Emilia da Silva (Orgs.). As desigualdades de gênero e raça na América Latina no século XXI. Porto Alegre: Editora Fi, 2019a. p. 43-62.

TRÓl, Marcelo de. "Alianças monstruosas e desejantes contra o sequestro da política pela esfera estatal". Revista Periódicus, Salvador, v. 1, n. 11, p. 05-28, maio/out. 2019b. Disponível em https:ll portalseer.ufba.br/index.php/revistaperiodicus/article/view/28581. Acesso em 22/01/2020.

TRÓl, Marcelo de; COLLING, Leandro. "Antropofagia, dissidências e novas práticas: o Teatro Oficina". Revista Ambivalências, Aracaju, v. 4, n. 8, p. 125-146, dez. 2016. Disponível em http://www.seer.ufs. br/index.php/Ambivalencias/article/view/6004. Acesso em 16/01/2020.

TRÓl, Marcelo de; COLLING, Leandro. "Decolonizar o corpo: a universidade antropófaga". Revista Urdimento, Florianópolis, v. 1, n. 28, p. 108-124, jul. 2017. Disponível em hnttp://www.revistas.udesc. br/index.php/urdimento/article/view/9330. Acesso em 16/01/2020. 
TURNER, Victor. O processo ritual: estrutura e antiestrutura. Petrópolis: Vozes, 1974.

VERGUEIRO, Viviane. Por inflexões decoloniais de corpos e identidades de gênero inconformes: uma análise autoetnográfica da cisgeneridade como normatividade. 2015. Mestrado (Programa Multidisciplinar de Pós-graduação em Cultura e Sociedade) - Instituto de Humanidades, Artes e Ciências da Universidade Federal da Bahia, Salvador, BA, Brasil.

VIVEIROS DE CASTRO, Eduardo. Metafísicas canibais. São Paulo: Cosac Naify/N-1 edições, 2015.

Marcelo de Trói (troi.marcelo@ufba.br) é bacharel em Comunicação Social com habilitação em Jornalismo pela Universidade Estadual Paulista Júlio de Mesquita Filho, mestre em Cultura e Sociedade pelo Instituto de Humanidades, Artes e Ciências Professor Milton Santos (IHAC) UFBA) e doutorando no mesmo programa. Pesquisador do Núcleo de Pesquisa e Extensão em Culturas, Gêneros e Sexualidades (NuCuS) do IHAC/UFBA, onde atua como um dos coordenadores da linha de pesquisa Corpos, Cidades e Territorialidades Dissidentes.

\section{COMO CITAR ESSE ARTIGO DE ACORDO COM AS NORMAS DA REVISTA}

TRÓ, Marcelo de. "Rastros de 1968 nos artivismos das dissidências sexuais e de gênero". Revista Estudos Feministas, Florianópolis, v. 29, n. 1, e62773, 2021.

\section{CONTRIBUIÇĀO DE AUTORIA}

Não se aplica.

\section{FINANCIAMENTO}

Conselho Nacional de Desenvolvimento Científico e Tecnológico (CNPq)

\section{CONSENTIMENTO DE USO DE IMAGEM}

Não se aplica

\section{APROVAÇĀO DE COMITÊ DE ÉTICA EM PESQUISA}

Não se aplica.

\section{CONFLITO DE INTERESSES}

Não se aplica.

\section{LICENÇA DE USO}

Este artigo está licenciado sob a Licença Creative Commons CC-BY 4.0 International. Com essa licença você pode compartilhar, adaptar, criar para qualquer fim, desde que atribua a autoria da obra.

\section{HISTÓRICO}

Recebido em 29/03/2019

Reapresentado em 23/01/2020

Aprovado em 27/05/2020

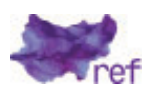

